\title{
Identitas Sosial Remaja Suku Mandar dalam Pappasang: Implikasi Bagi Penyusunan Bahan Bimbingan
}

\author{
Andy Wahyu Irawan ${ }^{1}$, Andi Mappiare-AT ${ }^{2}$, Muslihati Muslihati ${ }^{2}$ \\ ${ }^{1}$ Program Studi Bimbingan dan Konseling, Fakultas Keguruan dan Ilmu Pendidikan, \\ Universitas Mulawarman, Jl. Kuora, Samarinda, Kalimantan Timur, Indonesia 75119 \\ ${ }^{2}$ Jurusan Bimbingan dan Konseling, Fakultas Ilmu Pendidikan, Universitas Negeri Malang, \\ Jl. Semarang No. 5, Malang, Jawa Timur, Indonesia 65145 \\ E-mail: andiwahyuirawan@gmail.com
}

Artikel diterima: 2 Maret 2018; direvisi: 13 Juli 2018; disetujui: 14 Januari 2019

\begin{abstract}
Pappasang is a Mandar Tribe cultural product which contains advice. This advice has a characteristic describes the tribe identity of Mandar Tribe. This study aimed to examine the social identity of the Mandar Tribe adolescents in Pappasang as well as the foundation of guidance material. The qualitative study of gadamerian hermeneutics interpreted the social identity of Mandar Tribe adolescents in Pappasang. The findings showed the social identity are: empathy; remind each other; mutual help; solidarity; keep the disgrace on a secret; obedient; generous; democratic. Then, the social identity in Pappasang constructed to be material for guidance and counseling.
\end{abstract}

Keywords: social identity; advice; Pappasang; personal-social guidance; culture

\begin{abstract}
Abstrak: Pappasang merupakan produk budaya Suku Mandar yang berisi petuah. Petuah tersebut memiliki ciri khas yang menggambarkan identitas Suku Mandar. Penelitian ini bertujuan untuk mengkaji identitas sosial remaja Suku Mandar dalam Pappasang sekaligus menjadi konstruksi terhadap bahan bimbingan. Penelitian kualitatif hermeneutik gadamerian ini akan menafsirkan identitas sosial remaja Suku Mandar di dalam Pappasang. Temuan penelitian menunjukkan identitas sosial adalah: empati; saling mengingatkan; tolong menolong; solidaritas; menutup aib; taat; dermawan; dan demokratis. Identitas sosial dalam Pappasang kemudian dikontruksi untuk menjadi bahan bimbingan dan konseling.
\end{abstract}

Kata kunci: identitas sosial; petuah; Pappasang; bimbingan pribadi-sosial; budaya

Cepatnya proses globalisasi membawa perubahan yang cukup signifikan pada masyarakat (Suwardani, 2015). Salah satu contohnya adalah perubahan di kalangan remaja Suku Mandar. Lantaran semangat modernisasi, tatanan budaya Suku Mandar yang sebelumnya adalah budaya komunal mulai bergeser menjadi budaya individualistik. Kondisi ini menimbulkan benturan nilai antara identitas lokal dan hegemoni global. Perubahan geopolitik di Suku Mandar yang terjadi setelah pembentukan provinsi baru, juga turut berimbas pada keadaan sosial-budaya. Mandar menjadi ajang pertemuan budaya yang saling beradu dengan identitas yang lain. Remaja Suku Mandar dihadapkan pada banyak pilihan identitas dan nilai. Pilihan nilai yang beragam tersebut belum tentu baik dan cocok dengan kondisi sosial-budaya asli Suku Mandar. Jika kondisi tersebut terus-menerus terjadi, maka Suku Mandar akan kehilangan identitasnya. Hal ini dikarenakan kebudayaan hidup di dalam sistem sosial-budaya yang mengembangkannya (Kistanto, 2008), jika masyarakat tidak mengembangkan kebudayaan aslinya maka kebudayaan tersebut akan hilang. 
Pernyataan bahwa manusia adalah mahluk sosial yang tidak bisa hidup sendirian (Levy, Foulsham, \& Kingstone, 2013), perlu dipertanyakan kembali. Hal ini karena di kalangan remaja Suku Mandar selama kurun waktu tiga tahun terakhir terjadi fenomena yang menunjukkan sikap asosial. Di tahun 2016, terjadi tawuran antar sekolah, penyebabnya adalah perebutan pacar (Junaedi, 2016). Di tahun yang sama, belasan remaja Polewali Mandar ditangkap saat sahur karena pesta narkoba (Amisan, 2016). Di tahun 2017, seorang siswi Sekolah Menengah Atas ditemukan bunuh diri di rumahnya lantaran hubungan asmaranya tidak direstui oleh orangtuanya (Junaedi, 2017). Beberapa kasus tersebut tidak dapat digeneralisir terjadi pada semua remaja Suku Mandar, namun jika terus dibiarkan, tidak menutup kemungkinan kasus yang lain akan muncul kembali bahkan menjadi semakin kompleks.

Identitas adalah milik bersama, dimiliki secara bersama-sama oleh orang yang memiliki sejarah dan asal-usul yang sama (Wicandra, 2006). Identitas adalah suatu produksi, bukan esensi yang tetap dan menetap (Hall, 1996). Identitas individual ditengarai dinamis dalam kondisi tertentu, sedangkan identitas komunal menetap menjadi suatu ciri khas dalam masyarakat. Identitas komunal bisa jadi dikaji kembali, diceritakan turun temurun, dilestarikan melalui pelembagaan nilai atau dilupakan dari pikiran kolektif masyarakat. Identitas sosial merupakan kesadaran setiap individu bahwa ia merupakan bagian dari kelompok yang mencakup kesadaran perasaan dan nilai yang penting bagi individu sebagai bagian dari kelompok.

Sekolah adalah salah satu bentuk dari pelembagaan nilai yang mentranformasikan nilai ke dalam setiap aktivitas pembelajaran dan kehidupan di sekolah (Crossley dkk., 2017). Sekolah punya peran yang sangat vital dalam pembentukan identitas remaja. Kepercayaan orangtua dengan menitipkan anaknya untuk bersekolah adalah bentuk dari keyakinan jika sekolah bisa mendidik dan membentuk identitas anak menjadi lebih baik. Pelembagaan nilai tidak hanya sekedar mentransformasi moralitas dan etika, tapi juga penyesuaian berdasarkan latar budaya setempat. Melibatkan budaya dalam pendidikan adalah hal penting karena budaya merupakan instrumen kearifan lokal yang lahir dari pembacaan terhadap alam dan manusia. Melalui proses pendidikan, akan terjadi internalisasi budaya yang ada di tempat tersebut pada peserta didik. Salah satunya adalah menginternalisasikan Pappasang sebagai muatan dalam melakukan pelayanan bimbingan dan konseling.

Pappasang adalah petuah yang merupakan produk budaya dari Suku Mandar. Pappasang begitu diagungkan karena ia mampu mengetahui pikiran dan hati yang memerintahkan supaya masyarakat dapat menggunakan akal sehatnya (Syaeba, 2017). Pappasang dengan segala kekayaan nilai di dalamnya ditafsirkan sebagai pemersatu perbedaan (Muthalib, 1985). Ini berarti Pappasang berhubungan dengan kondisi pribadi-sosial manusia dalam berinteraksi satu sama lain. Pappasang sebagai identitas mampu menggambarkan karakteristik Suku Mandar.

Beberapa penelitian telah dilakukan untuk membahas Pappasang (Mandar); Pappaseng (Bugis) (Rahmi, Mappiare-AT, \& Muslihati, 2017)\& Paseng (Malik, 1997) serta bagaimana adopsi nilai dalam ketiga produk budaya tersebut ke dalam bimbingan dan konseling. Penelitian yang telah lalu tersebut mengkaji Pappaseng dan Paseng yang secara esensial mirip dengan Pappasang namun sejauh ini, belum ada penelitian yang membahas Pappasang milik Suku Mandar sebagai bahan untuk penyusunan bahan bimbingan.

Kajian mengenai identitas berada dalam seputaran keilmuan bimbingan dan konseling yang lebih spesifik mengarah pada bidang pribadi (Mappiare-AT, 2013a). Pertemuan budaya antar konselor sekolah dan konseli maupun antar konseli dengan konseli lainnya merupakan sebuah bentuk perkenalan identitas dan nilai. Dalam menghadapi krisis identitas yang terjadi karena upaya pewarisan nilai yang tidak ditransformasi dengan baik, mesti ada kontribusi bimbingan dan konseling dalam mempertegas identitas remaja. Penguatan identitas tersebut melibatkan budaya sebagai sebuah episentrum nilai dalam masyarakat. Pewarisan budaya merupakan salah satu tugas konselor sekolah melalui pengembangan aspek kemandirian konseli yang dapat menggunakan media layanan bernuansa budaya unggul (Mappiare-AT, 2010).

Bimbingan dan konseling sebagai praktik pewarisan nilai antara konselor sekolah ke konseli memiliki peran penting dalam upaya penegasan identitas. Identitas diperlukan sebagai penjelas siapa sebenarnya individu dalam suatu masyarakat (sekolah). Di dalam identitas, ada nilai-nilai 
yang diyakini dan dipegang teguh. Nilai tersebut akan menjadi penghalang terhadap pengaruh negatif dari luar diri. Praktik-praktik pendidikan dalam hal ini bimbingan dan konseling, perlu ikut merekonstuksi kearifan lokal sebagai sebuah teknik pewarisan nilai. Unsur-unsur kebaikan masa lampau, dibawa ke masa kini untuk kemudian dikontekskan dengan kondisi kehidupan modern. Bimbingan yang sesuai dengan kondisi sosial-budaya siswa akan efektif untuk membantu siswa berkembang dengan optimal (Nurrohman, 2014; Trisnani, Wardani, \& Puspita, 2016). Untuk itu, tujuan penelitian ini adalah mendeskripsikan identitas sosial remaja Suku Mandar dalam Pappasang dan mendeskripsikan konstuksi bahan bimbingan bermuatan Pappasang.

\section{METODE}

Untuk memahami Pappasang, peneliti menggunakan rancangan penelitian kualitatif berupa tipe hermeneutik gadamerian karena tipe tersebut menafsirkan simbol dan teks. Prosedur pengumpulan data dimulai dari mencari sumber data primer yaitu teks Pappasang dalam buku Local Wisdom: Untaian Mutiara dari Mandar (Idham, 2008). Teks dalam buku tersebut menggunakan bahasa Mandar dan artinya dalam bahasa Indonesia. Pemilihan buku sebagai sumber primer dengan pertimbangan bahwa hanya buku tersebut yang mengkategorisasikan Pappasang ke dalam beberapa bagian namun belum ditafsirkan secara hermeneutik. Pengumpulan data sekunder dilakukan melalui wawancara mendalam kepada budayawan Mandar untuk mengkonfirmasi kesesuaian teks dan tafsir terhadap teks tersebut. Reduksi data dilakukan melalui penetapan dan pengumpulan sumber yang sejalan dengan tujuan penelitian. Dalam prosedur pengumpulan data, peneliti melakukan seleksi untuk menemukan konsep yang lebih rinci mengenai tujuan penelitian.

Analisis data yang digunakan dalam penelitian mengikuti langkah-langkah Mappiare-AT (2013b) yang dimulai dari: (1) penafsiran bagian-bagian, unsur atau bagian (part), (2) penafsiran keseluruhan, keutuhan (whole), dan (3) mendapatkan pemahaman pada yang melandasi makna (understanding of underlying meaning). Pokok pemikiran hermeneutik gadamerian tertuang dalam lingkaran part and whole yang berpola naik turun untuk memahami makna teks. Untuk lebih jelas, lingkaran gadamerian disajikan pada gambar 1. Lingkaran pada gambar 1 bermakna bahwa part and whole digunakan untuk memahami teks secara utuh dengan melihat keseluruhan buku teks dengan tidak melupakan bagian penting dalam teks. Peneliti juga melakukan triangulasi data untuk mengecek keabsahan data. Triangulasi dilakukan antara hasil analisis teks Pappasang dengan hasil wawancara pada tokoh adat. Tokoh ada yang dimaksud adalah budayawan Mandar.

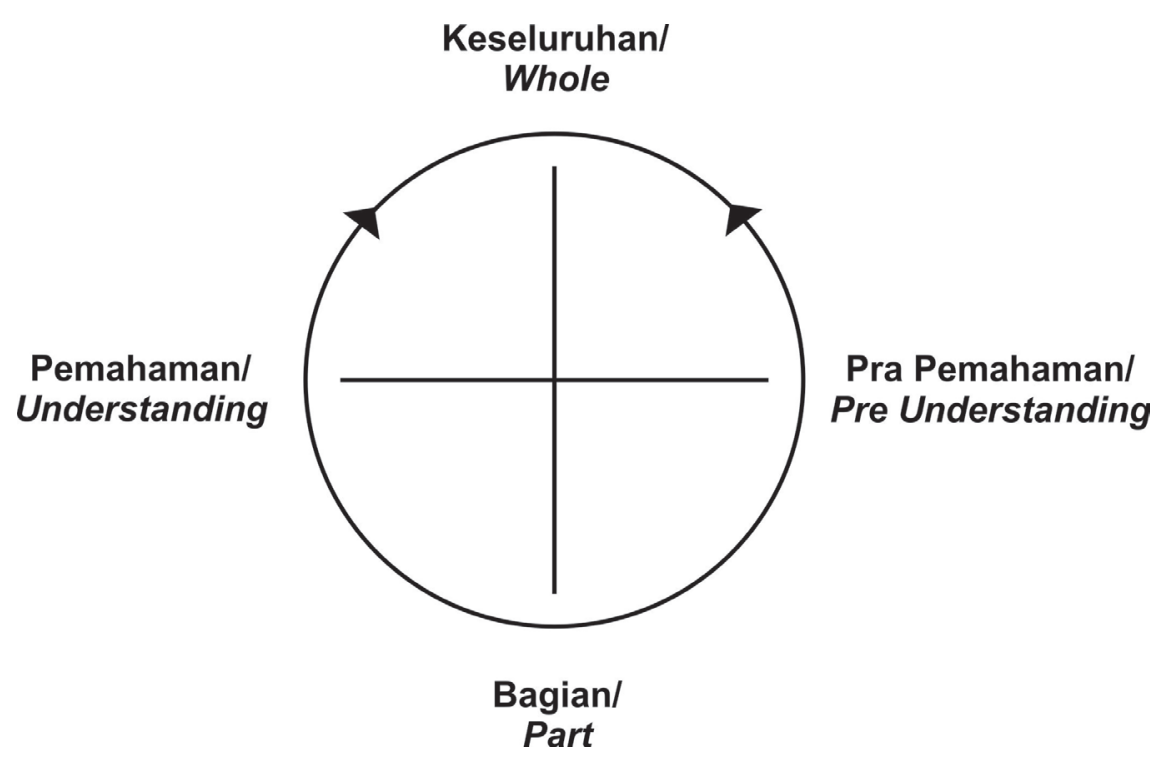

Gambar 1 Lingkaran Hermeneutik Gadamerian

Sumber: (Alvesson \& Sköldberg, 2017) 


\section{HASIL}

\section{Empati; Saling Mengingatkan; Tolong Menolong; dan Solidaritas}

Naruao lembong narua toa', tumbiringo'ona mallewaima', nyawa siandarang, cera silolongngi. (Engkau terkena ombak saya juga terkena, engkau goyah saya stabilkan, engkau tenggelam saya apungkan, jiwa melayang bersama, darah mengalir bersama)

Teks "engkau terkena ombak saya juga terkena" bermakna rasa empati yang perlu ada dalam diri Suku Mandar. Empati dalam konteks ini adalah sebuah kemampuan untuk merasakan keadaan emosional orang lain. Rasa empati sebagai bagian dari identitas sosial Suku Mandar dilihat dari keseharian Suku Mandar yang selalu peka terhadap keadaan. Malle boyang (memindahkan rumah) misalnya, menunjukkan empati Suku Mandar. Tradisi memindahkan rumah tersebut dilakukan secara gotong-royong untuk memindahkan rumah dari satu tempat ke tempat lain dengan cara diangkat bersama-sama, tanpa diminta pemilik rumah dan tanpa dibayar. Tradisi tersebut menunjukkan Suku Mandar merasakan apa yang dirasakan oleh sang empu rumah jika ia harus mencari orang dari kampung lain untuk mengangkat rumah atau bahkan membayar orang tersebut.

Teks selanjutnya, "engkau goyah saya stabilkan" bermakna bahwa Suku Mandar senantiasa memberikan peringatan dan mengajak pada kebaikan. "Engkau tenggelam saya apungkan" berarti Suku Mandar saling membantu dalam mencapai sesuatu yang lebih baik, bukan saling menjatuhkan. Dan teks terakhir adalah "darah mengalir bersama" berarti Suku Mandar percaya bahwa mereka dilahirkan dalam satu kejadian, sehingga mereka semua saling bersaudara. "Jiwa melayang bersama" bisa diartikan sebagai sebuah penegasan jika Suku Mandar memiliki solidaritas yang kuat.

Dari hasil wawancara yang dilakukan pada budayawan Mandar, rasa empati; senantiasa saling memperingatkan; tolong menolong; dan solidaritas yang tinggi disebut sebagai identitas sosial Suku Mandar. Budayawan Mandar berpendapat bahwa pada dasarnya Suku Mandar seharusnya mempunyai rasa empati; senantiasa saling memperingatkan; tolong menolong; dan solidaritas, dan Pappasang telah menyiratkan hal itu.

\footnotetext{
Mara'ba sipatokkong, malilu sipakainga', dibuttu, dilappar, andiangi tau mala sisara' mallulluare'. (Andai kita hanyut, rebah dan runtuh, marilah bersama-sama untuk tolong menolong. Andaikan kita saling khilaf, marilah saling mengingatkan baik di gunung maupun di daratan. Tidak ada sesuatu yang dapat memisahkan kekeluargaan kita sekalian.)
}

Teks "Andai kita hanyut, rebah dan runtuh, marilah bersama-sama untuk tolong menolong" bermakna sikap Suku Mandar yang tidak ingin jika sesamanya dijatuhkan sehingga perlu saling tolong menolong. Hanyut; rebah; dan runtuh, tiga kata yang maknanya hampir sama yang secara umum mengarah pada kondisi yang bermasalah. Teks "Andaikan kita saling khilaf, marilah saling mengingatkan baik di gunung maupun di daratan" merupakan sebuah komitmen empat belas Kerajaan Pitu Ulunna Salu (kerajaan di gunung) dan Kerajaan Pitu Baqbana Binanga (kerajaan di daratan) yang sepakat untuk saling menguatkan. Komitmen tersebut didasari pada kenyataan bahwa jika ada salah satu kerajaan yang mengalami masalah, maka kerajaan yang lain siap untuk menolong. Saling menguatkan antar kerajaan juga bermakna bahwa jika ada kerajaan dari luar yang menyerang, maka kerajaan yang lain siap untuk membantu.

Empat belas kerajaan yang berabad-abad lalu mendeklarasikan teks Pappasang dalam perjanjian Tammejarra 1 sekarang telah menjadi satu kabupaten dengan jargon Sulawesi Barat Malaqbi. Dalam konteks sipamandaq yaitu saling mengingatkan satu sama lain, empat belas kerajaan tersebut saling mengingatkan tetapi tidak saling mencampuri urusan masing-masing. Dalam konteks kondisi kekinian, manusia Mandar boleh saling mengingatkan tapi bukan berarti mencampuri urusan orang lain.

Kalimat "tidak ada sesuatu yang dapat memisahkan kekeluargaan kita sekalian" mempertegas bahwa sikap Suku Mandar memiliki solidaritas yang kuat. Kalimat "tidak ada sesuatu yang memisahkan kita" merujuk pada kondisi dan keadaan yang mengharuskan tidak ada perpecahan karena tidak ada sesuatu hal yang bisa memisahkan. 
Konsepsi tolong menolong dan solidaritas Suku Mandar juga ditunjukkan dalam kehidupan sehari-hari. Konsepsi sibaliparri (saling membantu) misalnya, dapat dilihat ketika seorang suami pergi melaut, maka sang istri mengganti tugas suami sebagai kepala rumah tangga. Istri menenun kain sutra Mandar untuk kemudian dijual sebagai tambahan penghasilan rumah tangga. Tugas-tugas rumah tangga seperti menjaga anak dan membereskan rumah dikerjakan oleh istri. Kondisi tersebut selain menunjukkan sikap saling tolong menolong, juga memperlihatkan sebuah solidaritas yang nyata dalam rumah tangga.

Pada saat melakukan konfirmasi kepada Budayawan Mandar tentang semua tafsiran teks yang telah ditulis melalui wawancara, Budayawan Mandar mengungkapkan bahwa identitas sosial Suku Mandar sama dengan tafsiran teks pertama, yaitu: senantiasa saling mengingatkan; tolong menolong; dan punya rasa solidaritas yang tinggi. Budayawan Mandar berpendapat keempat identitas tersebut perlu dilestarikan.

\section{Menutup Aib; Dermawan; Taat; dan Demokratis}

Pelipa'i to mellamba' anna pandei to tamba'i. (Beri sarung yang telanjang dan beri makan yang lapar)

Telanjang pada teks "beri sarung yang telanjang dan beri makan yang lapar" berupa aib yang mesti ditutupi. Telanjang merujuk pada kondisi yang memperlihatkan sesuatu yang seharusnya tidak diperlihatkan. Hal ini berarti, jangan mengumbar aib orang lain. Suku Mandar harus menutupi aib orang lain dengan segala kebaikannya. Konsep aib ini sama dengan konsepsi trilogi dari malaqbi, yaitu pau malaqbi atau tutur kata yang baik. Suku Mandar selalu menjaga tutur katanya agar tidak menyinggung hati orang lain. Menjaga tutur kata juga merupakan landasan pertama dalam mencapai kehidupan yang malaqbi. Sebelum sampai pada bagian yang lain yaitu kedo dan gauq malaqbi, Suku Mandar harus punya pau malaqbi. Dengan demikian, menjaga tutur kata adalah bagian yang penting dalam kehidupan Suku Mandar. Menjaga aib dengan cara bertutur kata yang baik saja akan berimplikasi terhadap segala kehidupan Suku Mandar.

Teks "beri makan yang lapar" berarti berusaha agar sesama manusia tidak merasakan penderitaan dan selalu memberi dalam kebaikan. Memberi makan yang lapar bermakna bahwa memberikan sesuatu bagi manusia yang kurang mampu. Suku Mandar percaya bahwa menjadi orang dermawan adalah sebuah bagian dari siklus hidup yang religius karena hidup di dunia hanya sementara, sehingga aspek religius mendominasi kehidupan. Pertanyaan: siapa?; dimana?; dan akan kemana? manusia pergi akan menjadi pertanyaan yang dijadikan sebagai pandangan hidup untuk menjalani kehidupan dunia.

Teks "beri sarung yang telanjang dan beri makan yang lapar" secara keseluruhan bermakna bahwa Suku Mandar selalu menutupi aib keluarga dan orang lain serta dermawan. Pemaknaan tersebut juga dibenarkan oleh budayawan Mandar menyebutkan bahwa kedua identitas sosial tersebut merupakan bagian dari hidup Suku Mandar.

Maroro titting tandi bassi', mua' direndengo'o atutui akke' lette'mu, mua' marrendengo'o pengilingo'o di pondo'mu. (Titilah pematang utuh lurus selurus-lurusnya, bila kau dibimbing hati-hati langkahkan kaki, jika kau menuntun, menolehlah ke belakangmu)

Titilah pematang utuh lurus selurus-lurusnya bermakna bahwa sebagai individu, seharusnya mengikuti aturan yang berlaku selurus-lurusnya, tidak boleh mengikuti jalan yang sesat atau melanggar aturan. Kalimat pertama tersebut menggambarkan sebuah ketaatan pada aturan yang mesti dijalankan. Pada kalimat kedua, diungkapkan "bila kau dibimbing hati-hati langkahkan kaki", hal ini diartikan Suku Mandar harus berarti hati-hati dalam berinteraksi dengan orang lain yang akan dijadikan contoh. Teks "jika kau menuntun, menolehlah ke belakangmu" bermakna agar setiap manusia selalu melihat kondisi di sekitarnya, jika jadi pemimpin melihat kondisi rakyatnya, jika menjadi orangtua, mendengar pendapat anaknya, dan jika menjadi teman, mendengar pendapat teman lainnya (selama itu baik). Kalimat tersebut bermakna bahwa di dalam kehidupan, harus senantiasa menjaga demokrasi. Demokrasi dalam konteks identitas sosial Suku Mandar, diartikan 
mendengar pendapat dari orang lain untuk mencapai kehidupan yang lebih baik. Identitas sosial yang bersifat demokratis diperlukan sebagai bagian dari keseimbangan hidup. Manusia tidak bisa hidup sendiri dan menentukan keputusan berdasarkan dirinya sendiri. Keseimbangan dengan mendengar pendapat orang lain akan membawa manusia pada kehidupan yang lebih baik. Budayawan Mandar membenarkan bahwa makna teks "jika kau menuntun, menolehlah ke belakangmu" berarti bahwa demokratis dan taat adalah bagian yang tidak terpisahkan dari kehidupan Suku Mandar.

\section{PEMBAHASAN}

\section{Pappasang Sebagai Representasi Identitas Suku Mandar}

Individu membangun identitasnya melalui identifikasi dirinya dan identifikasi orang lain berdasarkan: ras; Suku; budaya; bahasa dan agama (Deng, 2011). Definisi tersebut berarti mengarah pada keberadaan individu dalam suatu masyarakat dan responnya terhadap kondisi sosial-budaya yang ada. Sumber makna yang berasal dari identitas diterjemahkan menjadi pemaknaan individu (Castells, 2011). Individu berarti memiliki hak dan kuasa terhadap pengaruh lingkungan yang membangun identitasnya sehingga seorang individu dapat menolak atau menerima pengaruh lingkungan. Dalam kondisi tertentu, identitas dipengaruhi oleh: kolonialisasi; rasial; gender; dan konflik bangsa (Alcoff \& Mendieta, 2003). Salah satu contoh dari pengaruh kolonialisasi dan konflik bangsa pada identitas individu adalah ketika masa penjajahan di Indonesia. Ketika itu identitas Indonesia didefinisikan sebagai individu yang terjajah sumber daya alamnya. Kajian terhadap identitas tersebut menunjukkan bahwa identitas merupakan upaya dalam mengidentifikasi maupun diidentifikasi, sehingga identitas tidak menetap, melainkan dinamis.

Identitas sebagai representasi melalui wujud budaya tidak hanya dalam bentuk individual, tapi bersifat komunal. Identitas juga dimaknai sebagai penanda perbedaan yang merupakan representasi dalam sistem simbolik maupun sosial untuk melihat diri sendiri tidak seperti yang lain (Woodward, 1997). Hal ini berarti bahwa perbedaan dalam suatu masyarakat merupakan penanda yang membedakan identitas satu individu dengan yang lainnya.

Pappasang yang berisi petuah memiliki ciri khas pembeda dengan petuah pada umumnya. Perbedaan tersebut adalah keunikan nilai-nilai yang terkandung dalam Pappasang sebagai wujud dari identitas Suku Mandar. Studi yang mendalam terhadap sifat Suku Mandar sebagai suatu perwujudan identitas menunjukkan bahwa secara umum sifat Suku Mandar adalah: memegang teguh tradisi; suka menghargai tamu; patuh pada orang yang dipercayai; dan sering kali menunjukkan bukti keberanian pribadinya (Alimuddin, 2011).

Tempat atau lingkungan adalah pembentuk identitas komunal. Jika merujuk pada kondisi tersebut, kearifan lokal yang mencirikan masyarakat merupakan wujud dari identitas. Tidak heran jika wujud Suku Mandar disebutkan: lemah lembut dalam ucapan dan mulia perbuatan; menjaga agama dan menjaga harga diri; bila telah dibentangkan pantang dilangkahi bila telah diucapkan pantang dibelakangi (Idham, 2008). Identitas tersebut menjadi ciri khas Suku Mandar yang sekaligus mampu menjawab pertanyaan siapa sebenarnya Suku Mandar. Artinya, jika merujuk pada hasil penelitian, identitas sosial Suku Mandar yaitu: empati; saling mengingatkan; tolong menolong; solidaritas; menutup aib; taat; dermawan; dan demokratis.

Pappasang merupakan bagian dari kebudayaan Suku Mandar, sekaligus sebagai identitas Suku Mandar yang khas. Representasi terhadap pertanyaan siapa sebenarnya Suku Mandar, bisa ditemukan dalam Pappasang yang secara tekstual memuat pesan-pesan nilai yang tumbuh dan berkembang dari pembacaan terhadap alam dan manusia.

\section{Identitas Sosial Suku Mandar dalam Pappasang}

Identitas sosial Suku Mandar adalah: empati; saling mengingatkan; tolong menolong; solidaritas; menutup aib; taat; dermawan; dan demokratis. Empati yang ditafsirkan dari teks Pappasang "engkau terkena ombak saya juga terkena", secara simbolik melibatkan rasa pengertian antara satu individu 
dengan individu lainnya. Empati diartikan sebagai suatu kecenderungan yang dirasakan seseorang untuk merasakan sesuatu yang dilakukan oleh orang lain andai ia berada pada posisi dan situasi orang lain (Umar \& Ali, 1992). Empati berarti perasaan peduli terhadap perasaan orang lain.

Identitas sosial saling mengingatkan merujuk pada kondisi yang tidak stabil sehingga perlu distabilkan dengan cara saling mengingatkan. Saling mengingatkan bukan berarti mencampuri urusan orang lain, tetapi mengingatkan sesuatu yang mungkin dilupakan. Identitas tersebut ditambah dengan teks Pappasang "andaikan kita saling khilaf, marilah saling mengingatkan baik di gunung maupun di daratan".

Tolong menolong sebagai bagian dari identitas sosial Suku Mandar dalam teks Pappasang "engkau tenggelam saya apungkan", dimaknai sebagai bentuk pesan (petuah) agar Suku Mandar selalu tolong menolong satu sama lain. Solidaritas sebagai bentuk dari identitas sosial Suku Mandar dalam teks Pappasang "tidak ada sesuatu yang dapat memisahkan kekeluargaan kita sekalian" dan "jiwa melayang bersama, darah mengalir bersama" merupakan bentuk dari pengejawantahan identitas Suku Mandar. Solidaritas dilakukan sebagai bentuk dari kebersamaan dan rasa sesama Suku Mandar.

Menutup aib orang lain yang berlaku secara umum, juga berlaku bagi Suku Mandar. Teks Pappasang secara filosofis menyiratkan identitas tersebut dalam teks Pappasang "beri sarung yang telanjang". Telanjang dalam konteks ini dimaknai sebagai sesuatu yang tidak semestinya diperlihatkan. Aib seseorang, tidak semestinya diumbar kemana-mana. Sehingga menutup aib adalah sebuah keharusan yang mesti dijalankan oleh Suku Mandar.

Taat pada aturan pemerintah; adat; maupun masyarakat, merupakan identitas sosial Suku Mandar yang tidak kalah penting. Teks Pappasang "titilah pematang utuh lurus selurus-lurusnya" bermakna bahwa Suku Mandar harus menjalani hidup dan aturan yang lurus selurus-lurusnya. Taat dalam konteks ini berarti mengikuti aturan yang ada dalam masyarakat. Ketaatan menggambarkan bagaimana seharusnya Suku Mandar dalam menentukan sikap.

Identitas sosial dalam teks Pappasang "beri makan yang lapar" yang bermakna dermawan, menegaskan sebuah nilai yang diyakini oleh Suku Mandar yaitu lebih baik memberi daripada meminta. Kedermawanan menunjukkan sebuah sikap untuk peka terhadap kondisi sosial, tidak individual-materialistik

Demokratis sebagai suatu identitas sosial dalam teks Pappasang "jika kau menuntun, menolehlah kebelakangmu", memposisikan orang lain sebagai bagian dari individu. Manusia sebagai mahluk sosial berarti saling membutuhkan satu sama lain. Ketika demokratis menjadi istilah dalam kajian ini, maka orang lain diposisikan sebagai bagian dari individu yang mesti dilihat (menolehlah ke belakangmu). Maka, sebagai pemimpin dalam suatu masyarakat atau menjadi bagian dalam masyarakat, manusia harus memiliki suatu keseimbangan, di sisi lain menuntun, di sisi lain menoleh kebelakang.

\section{Identitas Sosial dalam Pappasang Sebagai Penyusunan Bahan Bimbingan}

Dewasa ini semakin banyak individu yang identitas dirinya belum sejalan dengan identitas lingkungannya. Konstruksi identitas yang tidak tegas semacam ini akan membuat individu terjebak pada keterasingan (alienasi) dengan segala konsekuensi pribadi-sosialnya (Mappiare, 2013). Konselor sekolah perlu memandirikan siswa dalam rangka mengkonstruksi dan rekonstruksi identitas sesuai dengan lingkungan sosial siswa. Kondisi ini meneguhkan peran penting konselor sekolah untuk menegaskan identitas konseli agar sesuai dengan kondisi yang semestinya. Untuk mempertegas identitas sosial konseli, diperlukan bahan bimbingan yang sesuai dengan kondisi sosial-budaya siswa. Hal ini dikarenakan bimbingan yang sesuai dengan kondisi sosial-budaya siswa akan efektif untuk membantu siswa berkembang dengan optimal (Nurrohman, 2014; Trisnani, Wardani, \& Puspita, 2016). Beberapa penelitian mengenai bahan bimbingan yang sesuai dengan kondisi-sosial budaya siswa adalah Serat Wedhatama (Istiqomah, Muslihati, \& Atmoko, 2017; Sutarno \& Barida, 2017); teks kepribadian Founding Fathers Indonesia (Ariyanto, Mappiare-AT, \& Irtadji, 2017); dan Nilai Budaya Lampung (Fitria, 2015). 
Proses penyusunan bahan bimbingan yang bersumber dari Pappasang dimaksudkan adalah dengan untuk menggabungkan unsur kata-kata dalam Pappasang menjadi sebuah bahan bimbingan yang dirangkumkan ke dalam kerangka konstruksi. Secara lebih jelas, kerangka konstruksi disajikan pada gambar 2. Kerangka bagian atas pada gambar 2 adalah persoalan remaja Suku Mandar yang mengalami pergeseran identitas. Penelusuran terhadap teks Pappasang menunjukkan ciri identitas sosial yang bisa digunakan sebagai bahan bimbingan dengan asumsi bahwa terdapat nilai-nilai yang prososial. Empati; saling mengingatkan; tolong menolong; solidaritas; taat; menutup aib; dan dermawan; adalah sikap dan nilai yang dapat ditemukan dalam Pappasang dan bukan hanya menjadi konseptual yang terminologis. Artinya sikap dan nilai dalam Pappasang bukanlah sebuah konsep dan kerangka kerja, tetapi sikap dan nilai tersebut adalah output dari identitas sosial yang ditemukan di Pappasang. Upaya menegaskan identitas sosial Suku Mandar dilakukan lewat penggunaan katakata dari Pappasang. Kata-kata tersebut dijadikan sebagai bahan bimbingan pribadi-sosial untuk menegaskan identitas sosial individu.

Dengan menggunakan Pappasang, konselor sekolah dapat meningkatkan sikap dan nilai konseli. Salah satu sikap tersebut adalah empati. Empati merupakan sikap yang dapat merefleksikan bagaimana seorang individu tumbuh dan berkembang (Bialystok \& Kukar, 2018). Empati dapat memberikan banyak manfaat untuk siswa. Manfaat tersebut antara lain: meningkatkan performa akademik (Cid-Sillero, Santiago-Ramajo, \& Martín-Lobo, 2018; Lee, Lee, \& Kim, 2018); meningkatkan kemampuan komunikasi dan penguasaan (Korte, Smith, \& Li, 2018); serta mengurangi kecenderungan melakukan bullying (Murphy, Tubritt, \& O'Higgins Norman, 2018).

Pemanfaatan Pappasang oleh konselor sekolah juga diharapkan dapat meningkatkan rasa solidaritas konseli. Rasa solidaritas dapat membuat seorang individu memiliki keinginan yang besar untuk meningkatkan keadilan sosial dan keadilan lingkungan (Torbjörnsson \& Molin, 2015). Solidaritas merupakan sebuah sikap yang penting, bahkan untuk konselor sekolah. Konselor sekolah yang memiliki rasa solidaritas pada konseli akan memberikan pelayanan yang lebih baik (TimmBottos, 2016). Siswa yang memiliki rasa solidaritas juga akan memiliki kepercayaan sosial yang tinggi (Flanagan \& Stout, 2010).

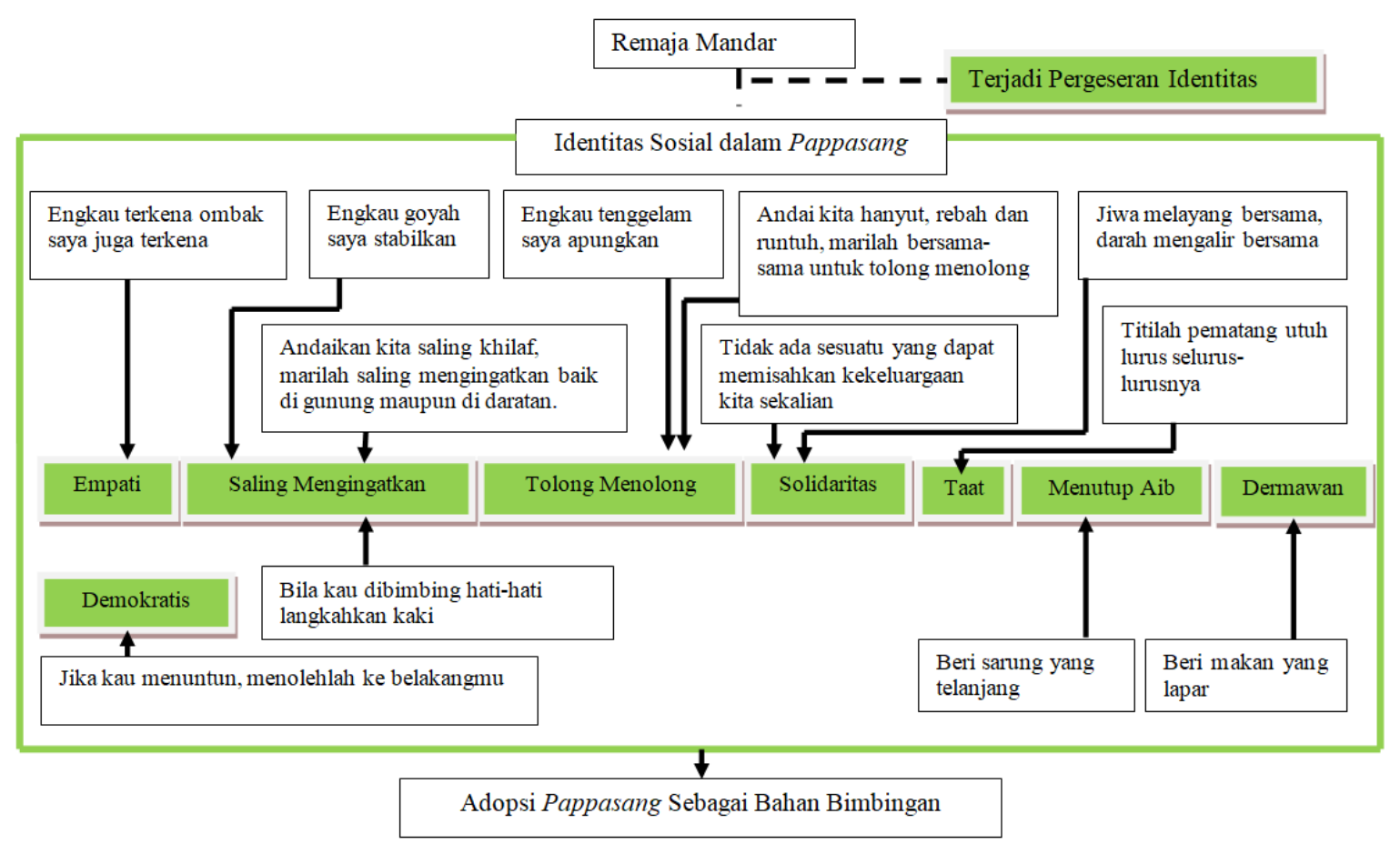

Gambar 2 Konstruksi Bahan Bimbingan dari Pappasang 
Taat terkadang dilakukan individu karena takut akan hukuman (Singer, Doornenbal, \& Okma, 2004; Wolfgang \& Kelsay, 1995). Konselor sekolah dan Guru adalah pemilik peran yang cukup penting untuk mengembangkan sikap taat siswa (Kamrath \& Brooker, 2017). Dengan menggunakan Pappasang, konselor sekolah dapat meningkatkan ketaatan konseli. Hal ini karena persepsi seorang individu pada ketaatan lebih dipengaruhi oleh guru dan konselor sekolah dibandingkan dengan keluarga (Sadik, 2018). Ketaatan dapat meningkatkan performa akademik murid (Simba, Agak, \& Kabuka, 2016) dan meningkatkan kepercayaan diri (Sugai \& Horner, 2002).

Konselor sekolah dapat menggunakan Pappasang sebagai bahan bimbingan untuk layanan informasi juga bibliokonseling. Layanan informasi untuk memberikan informasi kepada konseli dengan latar belakang Suku Mandar, bahwa Suku Mandar seharusnya mempunyai identitas yang tegas dengan ciri-ciri identitas sosial yang ada dalam Pappasang. Pappasang juga bisa digunakan dalam bentuk bibliokonseling atau bahan bacaan. Dengan menggunakan Pappasang sebagai bahan bacaan, sikap dan nilai yang terkadung di dalam Pappasang diharapkan mampu diinternalisasi oleh pembaca.

\section{SIMPULAN}

Pappasang merupakan produk budaya Suku Mandar yang berisi petuah. Petuah tersebut dapat digunakan konselor sekolah sebagai bahan bimbingan untuk membantu siswa berkembang secara optimal, khususnya siswa Suku Mandar. Dengan menggunakan Pappasang sebagai bahan layanan bimbingan, konselor sekolah dapat menumbuhkan beberapa sikap dan nilai konseli, yaitu: empati; saling mengingatkan; tolong menolong; solidaritas; menutup aib; taat; dermawan; dan demokratis. Penelitian selanjutnya dapat mengembangkan media bimbingan yang bermuatan sikap dan nilai dalam Pappasang.

\section{DAFTAR RUJUKAN}

Alcoff, L. M., \& Mendieta, E. (2003). Identities: Race, Class, Gender, and Nationality. MA: Blackwell Publishing Ltd.

Alimuddin, M. R. (2011). Polewali Mandar (Alam, Budaya, Manusia). Polman: Dinas Perhubungan, Komunikasi dan Informatika Kabupaten Polman.

Alvesson, M., \& Sköldberg, K. (2017). Reflexive Methodology: New Vistas for Qualitative Research. Sage.

Amisan, S. (2016). Belasan Remaja di Polewali Mandar Pesta Narkoba Saat Sahur. Diambil dari http://manado.tribunnews.com/2016/06/19/belasan-remaja-di-polewali-mandar-pesta-narkobasaat-sahur

Ariyanto, R. D., Mappiare-AT, A., \& Irtadji, M. (2017). Identifikasi Karakter Ideal Konseli Menurut Teks Kepribadian Founding Fathers Indonesia: Kajian Dalam Perspektif Fromm. Jurnal Pendidikan (Teori dan Praktik), 1(2), 174-182. https://doi.org/10.26740/jp.v1n2.p174-182

Bialystok, L., \& Kukar, P. (2018). Authenticity and Empathy in Education. Theory and Research in Education, 16(1), 23-39. https://doi.org/10.1177/1477878517746647

Castells, M. (2011). The Power of Identity (Vol. 14). John Wiley \& Sons.

Cid-Sillero, S., Santiago-Ramajo, S., \& Martín-Lobo, M. P. (2018). Relation between Executive Functions and Empathy and Their Influence on Academic Performance in Students of Basic Vocational Training. Electronic Journal of Research in Educational Psychology, 16(46), 517536.

Crossley, M., Koya Vaka'uta, C. F., Lagi, R., McGrath, S., Thaman, K. H., \& Waqailiti, L. (2017). Quality Education and The Role of The Teacher in Fiji: Mobilising Global and Local Values. Compare: A Journal of Comparative and International Education, 47(6), 872-890.

Deng, F. M. (2011). War of Visions: Conflict of Identities in The Sudan. Brookings Institution Press. Fitria, N. (2015). Bimbingan Kelompok Berbasis Tata Nilai Budaya Lampung untuk Meningkatkan Tingkah Laku Prososial Siswa. Jurnal Fokus Konseling, 1(2), 162-171. 
Flanagan, C. A., \& Stout, M. (2010). Developmental Patterns of Social Trust between Early and Late Adolescence: Age and School Climate Effects. Journal of Research on Adolescence, 20(3), $748-773$.

Hall, S. (1996). Who Needs Identity. Questions of Cultural Identity, 16(2), 1-17.

Idham, M. I. K. (2008). Local Wisdom: Benang Untaian Mutiara Hikmah dari Mandar, Sulawesi Barat. (NuQtah, Ed.). NuQtah.

Istiqomah, N., Muslihati, M., \& Atmoko, A. (2017). Work Value dalam Serat Wedhatama dan Implikasinya Terhadap Bimbingan Karier Berbasis Budaya Jawa. Jurnal Pendidikan: Teori, Penelitian, Dan Pengembangan, 2(6), 806-811.

Junaedi. (2016). Dipicu Rebutan Pacar, Siswa Dua SMA di Polewali Mandar Tawuran. Diambil dari http://regional.kompas.com/read/2016/09/20/19345491/dipicu.rebutan.pacar.siswa.dua.sma. di.polewali.mandar.tawuran

Junaedi. (2017). Siswa SMA Ditemukan Tergantung di Rumahnya. Diambil dari http://regional. kompas.com/read/2017/05/22/09135111/siswi.sma.ditemukan.tergantung.di.rumahnya

Kamrath, B., \& Brooker, T. (2017). Improved Attitude and Achievement: A Case Study of an Elementary School Academic Advisement Intervention. Professional School Counseling, 21(1), 1096-2409.

Kistanto, N. H. (2008). Sistem Sosial-Budaya di Indonesia. Sabda: Jurnal Kajian Kebudayaan, $3(2), 1-16$.

Korte, R., Smith, K. A., \& Li, C. Q. (2018). The Role of Empathy in Entrepreneurship: A Core Competency of the Entrepreneurial Mindset. Advances in Engineering Education, 7(1), 1-10.

Lee, J., Lee, Y., \& Kim, M. H. (2018). Effects of Empathy-based Learning in Elementary Social Studies. The Asia-Pacific Education Researcher, 27(6), 509-521.

Levy, J., Foulsham, T., \& Kingstone, A. (2013). Monsters are People Too. Biology Letters, 9(1), 20120850.

Malik, U. (1997). Kajian Nilai-nilai Paseng dan Kaitannya dengan Layanan Bimbingan SosialPribadi. (Tesis tidak diterbitkan) Universitas Negeri Malang.

Mappiare-AT, A. (2010). Revitalisasi dan Pewarisan Nilai Budaya Unggul Nusantara Melalui Media Bimbingan dan Konseling. Dalam Konferensi Nasional dan Workshop Asosiasi Psikologi Pendidikan Indonesia.

Mappiare-AT, A. (2013a). Penegasan Identitas Anak Bangsa Melalui Konseling Multibudaya Model KIPAS. Studium Jeneral kepada Dosen dan Mahasiswa Jurusan Bimbingan dan Konseling Islam Fakultas Dakwah dan Ilmu Komunikasi IAIN Sunan Ampel Surabaya. Surabaya.

Mappiare-AT, A. (2013b). Tipe-Tipe Metode Riset Kualitatif untuk Eksplanasi Sosial Budaya dan Bimbingan Konseling. Elang Mas \& Prodi Bimbingan dan Konseling Fakultas Ilmu Pendidikan Universitas Negeri Malang.

Murphy, H. R., Tubritt, J., \& O'Higgins Norman, J. (2018). The Role of Empathy in Preparing Teachers to Tackle Bullying. Journal of New Approaches in Educational Research, 7(1), 17-23. https://doi.org/10.7821/naer.2018.1.261

Muthalib, A. (1985). Pappasang dan Kalindaqdaq (Naskah Lontara Mandar). Balai Penelitian dan Pengkajian Kebudayan Sulawesi Selatan.

Nurrohman, H. (2014). Program Bimbingan dan Konseling Berbasis Nilai-Nilai Budaya untuk Meningkatkan Kemampuan Penyesuaian Diri Peserta Didik. Jurnal Penelitian Pendidikan, 14(1), 42-53.

Rahmi, S., Mappiare-AT, A., \& Muslihati, M. (2017). Karakter Ideal Konselor dalam Budaya Bugis Kajian Hermeneutik Terhadap Teks Pappaseng. Jurnal Pendidikan: Teori, Penelitian, Dan Pengembangan, 2(2), 228-237. 
Sadik, F. (2018). Children and Discipline: Investigating Secondary School Students' Perception of Discipline through Metaphors. European Journal of Educational Research, 7(1), 31-45.

Simba, N. O., Agak, J. O., \& Kabuka, E. K. (2016). Impact of Discipline on Academic Performance of Pupils in Public Primary Schools in Muhoroni Sub-County, Kenya. Journal of Education and Practice, 7(6), 164-173.

Singer, E., Doornenbal, J., \& Okma, K. (2004). Why do Children Resist or Obey Their Foster Parents? The Inner Logic of Children's Behavior During Discipline. Child Welfare, 83(6).

Sugai, G., \& Horner, R. (2002). The Evolution of Discipline Practices: School-Wide Positive Behavior Supports. Child \& Family Behavior Therapy, 24(1-2), 23-50. https://doi.org/10.1300/ J019v24n01_03

Sutarno, S., \& Barida, M. (2017). Kajian Bahan Bimbingan dan Konseling dalam Serat Wedhatama. Jurnal Kajian Bimbingan dan Konseling, 2(3), 114-122. https://doi.org/10.17977/ um001v2i32017p114

Suwardani, N. P. (2015). Pewarisan Nilai-nilai Kearifan Lokal untuk Memproteksi Masyarakat Bali dari Dampak Negatif Globalisasi. Jurnal Kajian Bali (Journal of Bali Studies), 5(2), 247-264.

Syaeba, M. (2017). Budaya Mandar Pappasang Hubungannya dengan Pembinaan Moral Masyarakat. Pepatudzu: Media Pendidikan dan Sosial Kemasyarakatan, 5(1), 1-14.

Timm-Bottos, J. (2016). Beyond Counseling and Psychotherapy, There Is a Field. I'll Meet You There. Art Therapy, 33(3), 160-162.

Torbjörnsson, T., \& Molin, L. (2015). In School We Have Not Time for The Future: Voices of Swedish Upper Secondary School Students About Solidarity and The Future. International Research in Geographical and Environmental Education, 24(4), 338-354.

Trisnani, R. P., Wardani, S. Y., \& Puspita, F. H. (2016). Efektifitas Bimbingan Kelompok Berbasis Budaya Jawa untuk Meningkatkan Komunikasi Interpersonal Siswa SMK PGRI Wonoasri. Counsellia: Jurnal Bimbingan dan Konseling, 6(1), 54-70.

Umar, M., \& Ali, A. (1992). Psikologi Umum. Surabaya: Bina Ilmu.

Wicandra, O. B. (2006). Graffiti di Indonesia: Sebuah Politik Identitas Ataukah Tren?(Kajian Politik Identitas pada Bomber di Surabaya). Nirmana, 8(2), 57.

Wolfgang, C. H., \& Kelsay, K. L. (1995). Discipline and The Social Studies Classroom, Grades K-12. The Social Studies, 86(4), 175-182. https://doi.org/10.1080/00377996.1995.9958392

Woodward, K. (1997). Identity and Difference (Vol. 3). Sage. 